\title{
Neuroendocrine neoplasms of the stomach
}

\author{
Oldrich Louthan†
}

\begin{abstract}
Background. Gastric neuroendocrine neoplasms of type 1 and type 3 are different entities and as such require different therapeutical strategies. The aim of this study was to define and distinguish these two tumour subtypes with clearly different biological properties and patient survival. As shown, serum gastrin is an important diagnostic tool for differentiating the less malignant type 1 "hypergastrinemia non-related" tumor from malignant type 3, along with other parameters of malignant potential such as proliferation index and depth of invasion.

Methods. The biological behaviour, tumour marker status, symptomatology, survival and therapeutical strategy were assessed and compared in 18 consecutive patients with type 1 and 7 with type 3 gastric neuroendocrine tumours.

Results. All 18 patients with type 1 gastric carcinoids survived long-term. 17/18 patients were treated with endoscopic tumour removal. The prognosis for patients with generalized type 3 neuroendocrine neoplasms was poor, with shortterm survival. No statistically significant differences between the types were found in urine 5 -hydroxyindolacetic acid concentration or serum chromogranin A concentration. Significant differences were found in serum gastrin with high levels even in localized type 1 tumors and normal levels in generalized type 3 neoplasm. Further, high neuron-specific enolase levels were found in type 3.

Conclusions. Type 1 tumour should be preferably treated with endoscopic tumour removal. Recently, favourable tumoristatic effects have been reported in somatostatin analogs. Surgery is a treatment option for type 3 neuroendocrine carcinoma with normal gastrinemia. Serum gastrin is suitable for assessment of the biological properties of both neuroendocrine neoplasm types. It serves, among other factors, as a predictor of prognosis and an indicator for the selection of optimal therapeutical strategy.
\end{abstract}

Key words: gastric carcinoid, neuroendocrine carcinoma, gastrin, chromogranin A, neuronspecific enolase

Received: November 3, 2012; Accepted with revision: June 5, 2013; Available online: June 27, 2013

http://dx.doi.org/10.5507/bp.2013.045

$4^{\text {th }}$ Internal Department, General University Hospital, Prague, Czech Republic

Corresponding author: Oldrich Louthan, e-mail:Louthan@post.cz

\section{INTRODUCTION}

Gastro-entero-pancreatic neuroendocrine neoplasms comprise a very heterogeneous group. They are usually malignant tumours with lower malignant potential but the yearly incidence is on the rise. The WHO tumour classification for 2010 provided new insights into neuroendocrine neoplasms, including gastric neuroendocrine neoplasms. This classification, hormone status assessment and further aspects of the biological tumour behaviour are necessary preconditions for correct management ${ }^{1}$. In 2012, ENETS (the European Neuroendocrine Tumor Society) introduced a new term: neuroendocrine neoplasm (NEN) as a general term for all neuroendocrine malignancies. According to WHO classification from 2010, neuroendocrine neoplasms are divided into (1) neuroendocrine tumours (NET) of grade G1 and grade G2 and (2) neuroendocrine carcinomas (NEC) grade G3 $\left(\right.$ ref. $\left.^{2,3}\right)$. For comparison, previous WHO from 2000 classified endocrine neoplasms (1) into well-differentiated neuroendocrine tumours (= G1), (2) well-differentiated endocrine carcinomas $(=\mathrm{G} 2)$, (3) poorly-differentiated endocrine carcinoma/small cell carcinomas $(=\mathrm{G} 3)\left(\right.$ ref. $\left.^{4}\right)$, see Table 1 .

In general, the concept of differentiation is related to the tumour grading but with subtle difference between differentiation and grade. Grade should be provided in the pathology report. The terms neuroendocrine tumour (NET) and neuroendocrine carcinoma (NEC) without exact grading are unqualified ${ }^{2}$.

If the grading is not indicated, information about tumor biological properties is insufficient to select an adequate therapeutical strategy.

According to the older but still widely used Rindi's classification $^{5}$, gastric neuroendocrine neoplasms are divided into type 1 (well-differentiated tumours), type 2 (well-differentiated) and type 3 (well or moderately differentiated). Poorly differentiated gastric neuroendocrine carcinomas (PDEC) were classified separately from gastric type 3 in previous ENETS guidelines from 2006, but the recent classsification published in ENETS Guidelines in 2012 (ref. ${ }^{1}$ ) includes G3 neuroendocrine carcinomas to type 3 gastric NEN.

There are three types of gastric neuroendocrine neoplasms. Neuroendocrine tumours (carcinoids) type 1 and neuroendocrine carcinomas (type 3 ) distinctly differ in biological and clinicopathological characteristics and require different management (see Table 2).

A more conservative approach is preferred in type 1 gastric neuroendocrine tumours, in contrast to the clearly malignant type 3 gastric neuroendocrine carcinomas in 
Table 1. Grading of neuroendocrine neoplasms.

\begin{tabular}{lccll}
\hline Grading & $\begin{array}{c}\text { Mitotic } \\
\text { index 10 HPF }\end{array}$ & $\begin{array}{c}\text { Proliferation } \\
\text { Index Ki67 (\%) }\end{array}$ & $\begin{array}{l}\text { WHO } \\
\text { Classification 2000 }\end{array}$ & $\begin{array}{l}\text { WHO } \\
\text { Classification 2010 }\end{array}$ \\
\hline G1 & $<2$ & $\leq 2$ & $\begin{array}{l}\text { Well-differentiated endocrine } \\
\text { tumour }\end{array}$ & NET G1 (carcinoid) \\
\hline G2 & $2-20$ & $3-20$ & $\begin{array}{l}\text { Well-differentiated endocrine } \\
\text { carcinoma }\end{array}$ & NET G2 \\
\hline G3 & $>20$ & $>\begin{array}{l}\text { Poorly-differentiated endocrine } \\
\text { carcinoma/small cell carcinoma }\end{array}$ & $\begin{array}{l}\text { NEC G3 large-cell or } \\
\text { small-cell type }\end{array}$ \\
\hline
\end{tabular}

$\mathrm{HPF}=$ high power field $=2 \mathrm{~cm}^{2}$, at least 40 fields evaluated at the area of highest mitotic density

Ki67 (MIB1 antibody; \% out of 2000 cells at the area of the most dense nuclei labeling)

Table 2. Three types of gastric neuroendocrine neoplasms.

\begin{tabular}{|c|c|c|c|}
\hline & Type 1 & Type 2 & Type 3 \\
\hline Proportion (\%) & $70-85$ & $5-6$ & $14-20$ \\
\hline Characteristics & $\begin{array}{c}<1-2 \mathrm{~cm}, \text { multifocal, } \\
\text { polypoid }\end{array}$ & $\begin{array}{c}<1-2 \mathrm{~cm}, \text { multifocal } \\
\text { polypoid }\end{array}$ & $\begin{array}{c}\text { Solitary, > } 2 \mathrm{~cm}, \text { polypoid, exul- } \\
\text { ceration }\end{array}$ \\
\hline Associated conditions & $\begin{array}{c}\text { Diffuse corporal atrophic } \\
\text { gastritis with hypergastrin- } \\
\text { emia }\end{array}$ & $\begin{array}{c}\text { ZES/MEN1 } \\
\text { hypergastrinemia }\end{array}$ & 0 , normal serum gastrin level \\
\hline Histology & Usually NET G1 & NET G1/G2 & NEC G3 \\
\hline Serum gastrin level & $\uparrow$ & $\uparrow$ & normal \\
\hline Gastric $\mathrm{pH}$ & $\uparrow \uparrow$ & $\downarrow \downarrow$ & normal \\
\hline Metastases (\%) & $2-5$ & $10-30$ & $50-100$ \\
\hline Tumor-related death (\%) & 0 & $<10$ & $25-30$ \\
\hline
\end{tabular}

(According to ENETS Consensus Guidelines for the Management of Patients with Gastroduodenal Neoplasms. Neurocrinology 2012;95:74-87. doi:10.1159/000335595)

which surgery is the method of choice, if feasible, and palliative chemotherapy in advanced cases ${ }^{6}$.

Type 1 is associated with diffuse corporal atrophic gastritis with hypergastrinemia. Gastrin exerts trophic effects on gastric ECL cells with subsequent hyperplasia and transformation into carcinoid cells ${ }^{7-9}$. Pernicious anemia is also a well- recognized association. Type 1 is a well-differentiated tumour, usually grade $\mathrm{G} 1$, rarely $\mathrm{G} 2$. Type 2 is a rare tumour, associated with Zollinger-Ellison syndrome (ZES), grade G1 or G2, often as a part of multiple endocrine neoplasia $1(\mathrm{MEN} 1)\left(\right.$ ref. $\left.^{8}\right)$. This type was not observed in our sample and will not be mentioned further. According to the ENETS guidelines from 2012 (ref. ${ }^{1}$ ), type 3 is usually G3, solitary neoplasm with higher mitotic activity Ki67 greater than 20\% (ref. ${ }^{10}$ ). Type 3 occurs in non-hypergastrinemic patients, in contrast to hypergastrinemia in type 1 and type 2 gastric NENs.

\section{PATIENTS AND METHODS}

\section{Sample characteristics}

Twenty-five consecutive Caucasian patients (16 females and 9 males) with gastric neuroendocrine neo- plasms were diagnosed and treated at the Center for Neuroendocrine Tumours of the $4^{\text {th }}$ Internal Department, General University Hospital in Prague, Czech Republic, between December 1994 to November 2011. 18 patients with type 1 gastric neuroendocrine neoplasm and 7 patients with type 3 gastric neuroendocrine neoplasm were included. The biological behaviour of the tumors, prognosis and treatment option were assessed with respect to primary tumour size, location, depth of invasion, grading and tumour marker status.

Serum gastrin, chromogranin A, neuron-specific enolase and urine 5-hydroxyindolacetic acid were evaluated in type 1 and type 3 gastric neuroendocrine neoplasms.

The median age of 18 patients with type 1 gastric NETs at the time of diagnosis was 60 years, ranging from 41 years to 74 years. There were 4 males and 14 females, male-to-female ratio approximately $1: 3$. This ratio with female prevalence is typical for type 1 gastric carcinoids. There was no significant difference in the age of the males and females.

The median age of 7 patients with type 3 gastric NECs was 66 years, ranging from 47 years to 85 years. There were 5 males and 2 females with a male-to-female ratio $2.5: 1$. 
Table 3. Basic demographic and pathologic data.

\begin{tabular}{ccc}
\hline & Type 1 NET (\%) & Type 3 NEC (\%) \\
\hline Age (median) & 60 (range 41-74) & 66 (range 47-85) \\
Female (\%) & $14(77.8)$ & $2(28.6)$ \\
Male (\%) & $4(22.2)$ & $5(71.4)$ \\
\hline Tumor site (\%) & $2 / 18(11.1)$ & $4 / 7(57.1)$ \\
\hline Upper 1/3 & $13 / 18(72.2)$ & $3 / 7(42.9)$ \\
Middle 1/3 & $3 / 18(16.7)$ & 0 \\
Lower 1/3 & $16 / 18(88.9)$ & 0 \\
\hline Grading & $2 / 18(11.1)$ & $3 / 7(42.9)$ \\
\hline G1 & 0 & $4 / 7(57.1)$ \\
\hline G3 & $0(0)$ & $6 / 7(85.7)$ \\
\hline Distant metastases (\%) & &
\end{tabular}

No statistically significant difference in age between type 1 and type 3 was found using the Mann-Whitney test ( $P=0.48)$.

The average follow-up period for both subsamples was 46.8 months, ranging from 6 months to 204 months details see in Table 3 .

\section{Biochemical tests}

Tumour markers were examined within routine practice at the Institute of Clinical Biochemistry and Laboratory Diagnostics, First Faculty of Medicine, Charles University in Prague and General University Hospital in Prague, Czech Republic.

CgA-RIA CT laboratory kits by Cisbio Bioassays (France) were used for in vitro quantitative measurement of chromogranin A in serum. CgA-RIACT is a solid-phase two-site immunoradiometric (IRMA) assay using two monoclonal antibodies prepared against sterically remote sites on the chromogranin A molecule. Reference range is $19.4-98.1 \mathrm{ng} / \mathrm{mL}$.

Neuron-specific enolase (NSE) was examined by ECLIA (electrochemiluminiscence immunoassay), using Modular Analytics E 170 analyzer, Roche Diagnostics, reference range $<16.3 \mathrm{ug} / \mathrm{L}$.

Serum gastrin was examined by RIA method using kits by CIS, France, reference range $28-115 \mathrm{mU} / \mathrm{L}$.

5-HIAA (5-hydroxyindolacetic acid) was tested in 24 $\mathrm{h}$ urine samples combined with hydrochloric acid additive to maintain $\mathrm{pH}$ below 3 , using photometric method, reference range is $\leq 50 \mathrm{umol} /$ day.

Informed consent was not required because the investigation was a part of routine clinical practice.

\section{Statistics}

Data normality was assessed by means of the ShapiroWilk test. Statistical significance was evaluated by the non-parametric Mann-Whitney test. Survival was evalu- ated by the Kaplan-Meier method. A $P$ value of 0.05 was considered statistically significant. The statistical software program STATISTICA CZ 9.1.210.0 was used.

\section{RESULTS}

\section{Type 1}

In total, 18 consecutive patients with type 1 were followed. Sixteen patients had G1 classification (88.8\%) and two patients had G2.

Type 1 carcinoids were located mainly in the middle third of the stomach (13/18), only $2 / 18$ in the upper third and $3 / 18$ in the lower part of the stomach (antrum pylori), see Table 3 . Neuroendocrine neoplasms of this type presented as dyspepsia (44.4\%), epigastric pain (22.2\%), iron-deficiency anemia in two patients (11.1\%), gastrointestinal bleeding caused by warfarin treatment indicated for atrial fibrillation in one patient $(5.6 \%)$. Pernicious anemia occurred in 5 patients $(27.5 \%)$. Weight loss was observed in two patients, one patient had tumour duplicity (gastric adenocarcinoma). More than one symptom occurred in some patients. No patients developed carcinoid syndrome, which is usual in this type of tumour ${ }^{11}$.

Somatostatin receptor scintigraphy (octreoscan) was positive in 4 persons out of 16 examined patients $(25 \%)$.

Invasion into mucosa/submucosa was observed in $15 / 18$ persons $(83.3 \%)$, invasion into lamina muscularis propria occurred only in three persons (16.7\%).

Treatment: $17 / 18$ patients were treated with endoscopic tumour removal, some patients were treated repeatedly due to tumour recurrence, only three patients with tumour invasion into muscularis mucosae and multiple recurring tumours underwent gastric resection (two out of those patients were previously treated with endoscopic resection as well). Just one patient underwent total gastrectomy for tumour duplicity (gastric adenocarcinoma). 
Treatment: Type 1 tumours should be preferably treated with endoscopic removal, or recently, with somatostatin analogs. Antrectomy may be indicated in frequently recurring type 1 tumours ${ }^{12}$, but total gastrectomy should be a rather exceptional indication for this type. Tumoristatic effects of somatostatin analogs have been confirmed by a few small clinical studies ${ }^{13-18}$. Somatostatin analog (octreotide) was used in our work with good therapeutical effect in 6 patients with recurring small multiple tumour lesions. Those patients were treated with more sequential approaches (endoscopic gastric resection and somatostatin analogs) due to tumour recurrence (see Table 4). Argon plasma coagulation was used in one patient with multiple small lesions, with good therapeutical effect.

Survival: 17 patients showed long-term survival, only one female patient with type 1 died, due to tumour duplicity (gastric adenocarcinoma); her survival was 7 months. Other patients survived without any signs of generalization.

\section{Type 3}

In total, 7 patients with this tumor type were followed. Three patients had G2 grading and four patients G3 grading ( 2 of them had small-cell cancers). Not all neoplasms in this subgroup met the criteria for grade $\mathrm{G} 3$, as required by the novel classification. But all these tumours were gastrin-independent and sporadic, 6/7 cases metastasizing at the time of diagnosis. For this reason, they were included in type 3. Their prognosis was poor (see Table 4). All but one patient were referred to our clinic with generalized cancers. Liver metastases were present in all but one patient. The exception was a female patient with advanced cancer at the time of diagnosis (see below). In addition, abdominal lymphnode involvement was detectable in two patients and bone metastases were present in one patient. Octreoscan was positive in $3 / 6$ patients $(50 \%)$.

Type 3 tumors were located mainly in the upper part of the stomach (4/7) - in cardia or proximal part of the stomach body, and 3/7 tumours were located in the middle part (corpus). No type 3 tumours were located in the lower part of the stomach.

Six out of seven patients with type 3 had weight loss. Abdominal pain appeared in two patients, hematemesis occurred in one patient. Carcinoid syndrome was not present in any patient.

Treatment: Surgery is a method of choice, if feasible. However, 6/7 cases were generalized at the time of diagnosis, and not even palliative surgery was feasible. Only one case presented as advanced cancer with invasion into regional lymphnodes and spleen, without liver metastases. This above-mentioned female patient was treated with gastrectomy, splenectomy and regional lympnodes removal, 3 patients were treated with dacarbazin-based chemotherapy (without response) and 3 with somatostatin analogs with an attempt to achieve tumoristatic effect (without response). Two patients were only treated symptomatically because of poor performance status.

Survival: In contrast to type 1, the prognosis for patients with generalized type 3 neuroendocrine neoplasms was poor with short-term survival irrespective of chosen palliative procedures. Irrespective of being G2 or G3, median survival of generalized cases was only 3 months, range 1 - 6 months. Just one female patient mentioned, after radical surgery (gastrectomy and splenectomy) survived 204 months (since 1994), and in the end, she died of recurring episodes of aspiration pneumonia as a complication following gastrectomy.

Table 4. Therapeutical procedures in both subsamples.

\begin{tabular}{lcc}
\hline \multicolumn{1}{c}{ Therapy } & Type 1 & Type 3 \\
\hline Endoscopic removal & $17 / 18$ & $0 / 7$ \\
Gastric resection & $3 / 18$ & $0 / 7$ \\
Argon plasma coagulation & $1 / 18$ & $0 / 7$ \\
Gastrectomy & $1 / 18$ & $1 / 7$ \\
Somatostatin analogs & $6 / 18$ & $3 / 7$ \\
And/or chemotherapy & $0 / 18$ & $3 / 7$ \\
Symptomatic treatment & $0 / 18$ & $2 / 7$ \\
\hline
\end{tabular}

Comparison of laboratory tests shows the following data: no significant difference was found in 5-HIAA urine concentration between subsamples with type 1 versus type 3 , with $P=0.3322$, which confirms the widely accepted opinion that there is no reason for routine testing of 5-HIAA in gastric neuroendocrine neoplasms.

Median of neuron-specific enolase (NSE) serum concentration was normal in type 1 with median $13 \mathrm{ug} / \mathrm{L}$ (95\% CI: 11.15 - 14.13), but highly elevated in type 3 with median 327.9 (95\% CI: 19.29 - 740), with a highly significant difference between the groups $P=0.0066$. However, in fact, these data are not commensurable because all type 1 neoplasms were localized but 6/7 cases with type 3 were generalized. In general, high levels of NSE portend poorer prognosis in poorly-differentiated neuroendocrine neoplasms.

Serum chromogranin A ( $\mathrm{S}-\mathrm{CgA})$ level is increased in both types: median $272 \mathrm{ng} / \mathrm{mL}$ (95\% CI 128.5 - 517.6) in localized tumours type 1, and median $583 \mathrm{ng} / \mathrm{mL}(95 \%$ CI 158.8 - 945.8) in generalized tumors type 3. Even if chromogranin level is higher in type 3 , this difference is insignificant at $P=0.21$. Therefore, validity of $\mathrm{S}-\mathrm{CgA}$ for differentiation of type 1 and generalized type 3 is limited.

On the contrary, serum gastrin level is an important and valid indicator for distinguishing type 1 from type 3 irrespective of grading. In our sample, serum gastrin was examined in 15/18 patients with type 1 and gastrin level was increased in all 15 patients. Median serum gastrin was $847 \mathrm{mU} / \mathrm{L}$ (95\% CI: 571.34 - 1811.03). On the other hand, gastrin level in type 3 carcinomas was slightly increased only in one patient and normal in $6 / 7$ patients - $66.3 \mathrm{mU} / \mathrm{L}$ (95\% CI: 41.82 - 171.28). Thus, gastrin level is normal in gastrin-independent type 3 . This difference between types 1 and 3 is statistically highly significant at $P<0.0001$ (see Fig. 1). 


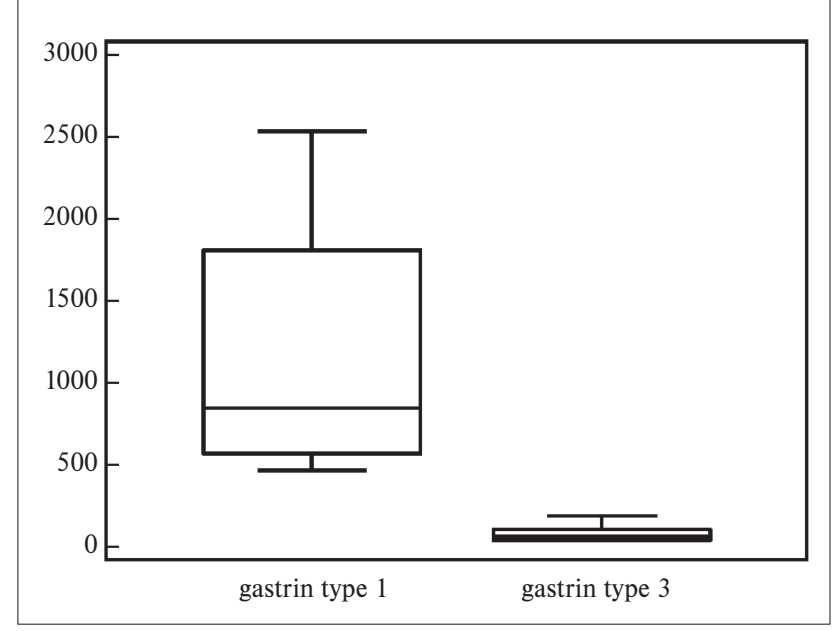

Fig. 1. Serum gastrin levels in type 1 and type 3 gastric NENs.

\section{DISCUSSION}

As known from the literature and confirmed by our report, the prognosis of type 1 gastric neuroendocrine tumours is very good: 17 out of 18 of our patients treated mostly with conservative approaches such as endoscopic resection, somatostatin analogs, argon laser coagulation, survived for a long time.

On the other hand, six out of seven malignant neoplasms type 3, whether $\mathrm{G} 2$ neuroendocrine tumour subgroup (3/7 patients) or G3 neuroendocrine carcinoma subgroup (4/7 patients) (see Table 3) displayed very poor prognosis, worse than the prognosis in the sample of type 3 cases reported by Kim BS et al. ${ }^{19}$ Generalized inoperable cancers with multiple liver metastases were diagnosed in 6 out of $7(85.7 \%)$ patients at the time of diagnosis. Disease progression was rapid and response to palliative treatment limited, if any. Median survival was only 3 months irrespective of palliative treatment. The discrepancy in survival between our sample and Kim BS et al. ${ }^{19}$ sample may be partly explained by the fact that G3 tumors in our sample were included in type 3, according to the ENETS Guidelines for 2012, but Kim BS et al. ${ }^{19}$ classified neuroendocrine carcinomas separately from type 3. In practice, care should be also taken to separate poorly-differentiated carcinomas (PDEC) from mixed exocrine-endocrine tumours. PDEC tumor cells are strongly positive for cytosolic markers such as neuron-specific enolase (NSE) and PGP9.5 but show weak positivity or negativity for chromogranin A. Positive staining for synaptophysin may be the only marker of neuroendocrine differentiation in those cases ${ }^{6}$.

As regards carcinoid of "unknown type" (vague atrophy of gastric mucosa) mentioned by Kim BS et al. ${ }^{19}$, this entity is not recently classified in this new nomenclature. It should be probably classified as type 1 .

Gastric neuroendocrine neoplasms type 1 and type 3 are clearly different entities with different biological behavior, prognosis, and they deserve different therapeutical strategy.
Grading is one of the important factors for indications for surgery (along with depth of invasion, tumor size and involvement of regional lymphnodes). The Ki67 index is convenient for the limited amount of tumour tissue when it may be difficult to perform an accurate mitotic count. If adequate tissue is available to perform mitotic index, the Ki67 index is not necessary. Interestingly, in some cases, both parameters, i.e. mitotic index and Ki67 may provide conflicting data about grading ${ }^{2}$. In our opinion, most patients with type 1, with grading G1 (Ki67 $\leq 2 \%$ ), tumor size $\leq 10 \mathrm{~mm}$, tumours not penetrating through lamina muscularis mucosae and not metastasizing into regional lymphnodes canmostly be treated by endoscopic removal. Antrectomy may be considered for recurrent cases ${ }^{12}$, however, according to some authors, the long-term benefits of antrectomy remain uncertain ${ }^{15}$.

Serum chromogranin A levels were increased in both subsamples and did not differ significantly even though type 1 tumours were only localized, small lesions (tumour size was up to $10 \mathrm{~mm}$ in diameter in our subsample), and type 3 tumors were generalized with large tumour load. This discrepancy can be explained by the fact that high $\mathrm{CgA}$ levels in generalized neoplasms of type 3 reflect large tumor mass; however, high concentrations of $\mathrm{CgA}$ in type 1 reflect high production of CgA by ECL gastric cells of the oxynthic mucosa stimulated by hypergastrinemia due to gastrin over-production by gastric G-cells. In practice, it is also necessary to verify if serum chromogranin A is not falsely elevated due to proton pump inhibitor treatment, which often happens in the practice.

Serum neuron-specific enolase (NSE) concentration is high in rapidly growing, aggressive type 3 neuroendocrine carcinomas with large tumour load, and, for this reason, high concentrations of this enzyme are frequent in generalized cancers type 3 with grading G3. High levels of NSE portend poorer prognosis. On the other hand, normal concentrations in slow-growing well-differentiated type 1 tumours are common.

In our opinion, serum gastrin is a reliable diagnostic tool for differentiation of "hypergastrinemia-related" less malignant, well-differentiated type 1 from clearly malignant, poorly-differentiated "hypergastrinemia-nonrelated" type 3. Gastrin may serve, along with other mentioned factors, as one of the predictors of prognosis and an indicator for the selection of optimal therapeutical strategy. Further criteria, such as depth of invasion and tumor size should be assessed at choosing the most benefitial therapeutical procedure for type 1 - whether endoscopic resection, somatostatin analogs ${ }^{16}$ or surgery.

\section{CONCLUSIONS}

Despite the small number of patients, the results are consistent with other published data and provide the basis for certain conclusions.

In type 1 gastric gastrin-dependent carcinoids, endoscopic management with lesion removal should be clearly preferred, surgery should be limited to larger tu- 
mors (greater than $10 \mathrm{~mm}$ ), tumours invading beyond lamina muscularis propria of the stomach or to the grade 2 tumours and lymphnode metastases (however rare in type 1). In our opinion, total gastrectomy should be performed only exceptionally in special cases of type 1 gastric carcinoids.

It was confirmed that octreotide treatment is effective in reducing hypergastrinemia and associated ECL cell changes in patients with atrophic gastritis ${ }^{13}$. Thus, gastrin suppression and tumoristatic effect may be achieved using somatostatin analogs (octreotide or lanreotide) in recurrent and multiple lesion type 1 NETs or type 2 (ref. ${ }^{14-18,20}$ ). Antrectomy is also an effective procedure for gastrin suppression but debatable by some authors ${ }^{1}$.

On the other hand, surgery is clearly a therapeutical option, if feasible, for gastrin-independent type 3 neuroendocrine carcinoma. Surgery should be considered as a method of choice in these tumors with normal gastrinemia, even if other parameters (grading, size, depth of invasion etc.) may seem to be favourable and would be indication for endoscopic treatment in type 1 hypergastrinemia-related tumours only because, as mentioned, the prognosis of hypergastrinemia non-related tumours is clearly worse.

If surgery is not feasible in locally advanced or generalized cancers, then palliative methods based on ablative procedures, such as radiofrequency ablation or (chemo) embolisation ${ }^{21}$ or targeted radionuclide therapy ${ }^{22}$ may be considered. Somatostatin analogs are not effective in type 3 neuroendocrine carcinomas; palliative chemotherapy should be tried but response rate is rather low with shorttime duration ${ }^{6}$.

\section{ACKNOWLEDGEMENT}

This article is supported by the grants RVO VFN64165 and PRVOUK-P25/LF1/2.

Conflict of interest statement: The author stated that there is no conflict of interests regarding the publication of this article.

In the case of interest, please contact Prof. Ales Zak, e-mail:azak@vfn.cz.

\section{REFERENCES}

1. Delle Fave G, Kwekkeboom DJ, Van Cutsem E, Rindi G, Kos-Kudla B, Knigge U, Sasano H, Tomassetti P, Salazar R, Ruszniewski R. ENETS Consensus Guidelines for the Management of Patients with Gastroduodenal Neoplasms. Neuroendocrinology 2012;95:74-87.

2. Klimstra DS, Modlin IR, Coppola D, Lloyd RV, Suster S. The Pathologic Classification of Neuroendocrine Tumors. A review of Nomenclature, Grading, and Staging Systems. Consensus Guidelines for the
Diagnosis and Management of Neuroendocrine Tumors. NANETS Guidelines. Pancreas 2010;39:707-12.

3. Kulke HM, Anthony LB, Bushnell DL, de Herder WW, Goldsmith SJ, Klimstra DS, Marx SJ, Pasieka JL, Pommier RF, Yao JC, Jensen RT. Well-Differentiated Neuroendocrine Tumors of the Stomach and Pancreas. NANETS Guidelines 2010;39(6):735-52.

4. Solcia E, Kloppel G, Sobin LH. Histological typing of endocrine tumours; in Solcia E, Kloppel G, Sobin LH (eds): Histological Typing of Endocrine Tumours. International classification of Tumours, ed 2. Berlin, Springer, 2000.

5. Rindi G, Luinetti O, Cornaggia M, Capella C, Solcia E. Three subtypes of gastric argyrophil carcinoid and the gastric neuroendocrine carcinoma: a clinicopathologic study. Gastroenterology 1993;104(4):9941006.

6. Nilsson O, Cutsem EV, Delle Fave G, Yao JC, Pavel ME, McNicol AM. Poorly Differentiated Carcinomas of the Foregut (Gastric, Duodenal and Pancreatic). ENETS Guidelines. Neuroendocrinology 2006;84:212-5.

7. Bordi C, D'Adda T, Azzoni C. Hypergastrinemia and gastric enterochromaffin-like cells. Am J Surg 1995;19(Suppl 1):S8-19.

8. Lehy T, Cadiot G, Mignon M, Ruszniewski P, Bonfils S. Influence of multiple endocrine neoplasm type 1 on gastric endocrine cells in patients with Zollinger-Ellison syndrome. Gut 1992;33:1275-9.

9. Waldum HL, Sandvik AK, Idle JR. Gastrin is the most important factor in ECL tumorigenesis. Gastroenterology 1998;114:1113-5.

10. Ruszniewski P, Delle Fave G, Cadiot G, Cadiot G, Komminoth P, Chung D, Kos-Kudla B, Kianmanesh R, Hochhauser D, Arnold R, Ahlman H, Pauwels S, Kwekkeboom DJ, Rindi G; Frascati Consensus Conference; European neuroendocrine Tumor Society. Well-Differentiated Gastric Tumors/Carcinomas. Neuroendocrinology 2009;84(3):158-64.

11. Granberg D, Wilander E, Stridsberg M, Granerus G, Skogseid B, Öberg $\mathrm{K}$. Clinical symptoms, hormone profiles, treatment, and prognosis in patients with gastric carcinoids. Gut 1998;43,223-8.

12. Hirschowitz BI, Griffith J, Pellegrin D, Cummings OW. Rapid regression of enterochromaffin-like cell gastric carcinoids in pernicious anemia after antrectomy. Gastroenterology 1992;102:1409-18.

13. Ferraro G, Annibale B, Marignani M, Azzoni C, D'Adda T, D'Ambra G, Bordi $C$, delle Fave $G$. Effectiveness of octreotide in controlling fasting hypergastrinemia and related enterochromaffin-like cell growth. J Clin Endocrinol Metab 1996;81(2):677-83.

14. Fykse V, Sandvik AK, Qvigstad G, Falkmer GE, Syversen U, Waldum HL. Treatment of ECL cell carcinoids with octreotide LAR. Scandinavian Journal of Gastroenterology 2004;39(7):621-8.

15. Grozinsky-Glasberg S, Kaltsas G, Gur C, Gal E, Thomas D, Fichman S, Alexandraki K, Barak D, Glaser B, Shimon I, Gross DJ. Long-acting somatostatin analogues are an effective treatment for type 1 gastric carcinoid tumours. Eur J Endocrinol 2008;159:475-82.

16. Khuroo MS, Khuroo MS, Khuroo NS. Treatment of type I gastric neuroendocrine tumors with somatostatin analogs. J Gastroenterol Hepatol 2010;25(3):548-54

17. Hou W, Schubert ML. Treatment of gastric carcinoids. Curr Treat Options Gastroenterol 2007;10(2):123-33.

18. Arnold R, Simon B, Wied M. Treatment of Neuroendocrine GEP Tumours with Somatostatin Analogues. Digestion 2000;62(Suppl.1):84-91.

19. Kim BS, Oh ST, Yook JH, Kim KC, Kim MG, Jeong JW, Kim BS. Typical carcinoids and neuroendocrine carcinomas of the stomach: differing clinical courses and prognoses. Am J Surg 2010;3:328-33.

20. Tomassetti P, Migliori M, Caletti GC, Fusaroli P, Corinaldesi R, Gullo L. Treatment of type II gastric carcinoid tumors with somatostatin analogues. N Eng J Med 2000;343:551-4.

21. Gupta S, Yao JC, Ahrar K, Wallace MJ, Morello FA, Madoff DC, Murthy R, Hicks ME, Ajani JA. Hepatic artery embolization and chemoembolization for treatment of patients with metastatic carcinoid tumors: the M.D. Anderson experience. Cancer J 2003;9(4):261-7.

22. Lewington VJ. Targeted radionuclide therapy for neuroendocrine tumour. Endocr Relat Cancer 2003;10,497-501. 